\title{
Ser assistente social: A formação académica em serviço social (Portugal) enquanto elemento estruturante e identitário
}

\author{
Being a social worker: The academic training in social work (Portugal) as a \\ structuring and identity element
}

Nídia Menezes ${ }^{1}$

\begin{abstract}
Resumo
No presente artigo pretendemos refletir em torno do Serviço Social em Portugal, mais especificamente sobre a formação académica ministrada em Serviço Social, recorrendo por isso a uma análise socio histórica da profissão em Portugal, de modo a refletir sobre o trajeto percorrido até à atualidade, bem como o impacto que as várias transformações sociais e políticas tiveram e têm na formação em Serviço Social. A reflexão desenvolvida privilegia a formação enquanto elemento estruturante e identitário da profissão. Refletir sobre o Serviço Social bem como sobre o seu contributo na sociedade, torna-se num exercício ininterrupto, sobretudo numa era em que os direitos sociais são ultrapassados pelas imposições neoliberais e marcados pela retração da responsabilidade estatal, implicando que o assistente social seja detentor de um pensamento crítico, reflexivo e político.
\end{abstract}

Palavras-chave: formação, serviço social, identidade.

\begin{abstract}
In this article, we intend to reflect on Social Work in Portugal, more specifically on Graduated Training given in Social Work, using therefore a socio-historical analysis of the profession in Portugal, in order to reflect on the path taken until today, as well as the impact that the various political social transformations had and have in the formation in Social Work. The reflection developed favors training as a structuring and identity element of the profession. Reflecting on Social Work as well as on its contribution to society, becomes an uninterrupted exercise, especially in an era in which social rights are overtaken by neoliberal impositions and marked by the retraction of state responsibility, implying that the social worker is the holder of critical, reflective and political thinking.
\end{abstract}

Keywords: training, social work, identity.

\section{Introdução}

O lugar do assistente social na sociedade é tão dinâmico quanto as relações sociais na medida em que atua na realidade social na sua vertente sistémica, conseguindo assim compreender o contexto das interações em que se movimentam os diferentes atores sociais. A intervenção destes profissionais bem como o seu contributo junto das demais áreas num novo paradigma civilizacional, carece como defende Amaro (2009) que se (re) pense o serviço social, enquanto área do conhecimento, onde as competências suplantam

\footnotetext{
${ }^{1}$ Assistente Social. Professora Adjunta na Escola Superior de Tecnologia e Gestão de Lamego-Politécnico de Viseu | E-mail: nmenezes@estgl.ipv.pt
} 
a experiência e a tecnologia, e a racionalidade técnico operativa refreia os sistemas sociais, mesmo que em categorias de dominação distintas.

Atualmente o serviço social tem de garantir o seu lugar nos demais contextos sociodemográficos, políticos, económicos, tecnológicos e culturais contemporâneos, por forma a melhorar ou desenvolver esses mesmos contextos. A formação e a qualificação, assumem uma dimensão basilar e reflexiva neste (re) posicionamento profissional.

Propomos assim refletir sobre a formação académica em serviço social ministrada em Portugal (universidade e politécnicos) inserida num quadro de mudanças sociais e políticas enfraquecedoras da capacidade do assistente social em promover a qualidade de vida, e a justiça social do cidadão exigindo para isso novas responsabilidades e a necessidade de (re) enquadrar professores e estudantes no ensino de serviço social.

Elaborámos um enquadramento teórico sobre a formação em serviço social a partir do caso português estabelecendo um paralelismo com as questões identitárias, refletindo de seguida sobre o debate académico do serviço social como área de conhecimento científico (ciência) mencionando a dimensão ética e reflexiva sobre a ação e o conhecimento. Por último debruçámo-nos sobre os desafios e potencialidades que se colocam à profissão por trama das mudanças sociodemográficas, políticas, económicas, tecnológicas e culturais contemporâneas. Nas conclusões deixamos um conjunto de inflexões e inquietações para debate e aprofundamento do tema.

\section{Formação em serviço social: o caso português}

A institucionalização do serviço social em Portugal teve início na década de 30 do século XX com a abertura da primeira escola de Serviço Social em Lisboa, nomeadamente, em 1935 do Instituto de Serviço Social em Lisboa e, em 1937, da Escola Normal Social em Coimbra e na década de cinquenta a Escola do Porto.

À semelhança do que ocorreu noutros países, para implementação das primeiras escolas de serviço social, também para Portugal vieram expressamente de França assistentes sociais para estabelecer e organizar este projeto educativo, alimentando a expectativa que o serviço social se tornasse num instrumento de concretização das ideias de intervenção na "questão social" e do projeto político de educação nacional - "Deus, Pátria e Família” (Silva, 2017, p.37) 
A história da União Católica Internacional de Serviço Social e a história do serviço social católico no mundo esteve presente nos programas das escolas de serviço social e Portugal foi exemplo disso tal como podemos constatar na figura (1) que se apresenta.

Figura 1. Tabelas de Escolas de Serviço Social filiadas na União Católica Internacional de Serviço Social em 1964

\begin{tabular}{|l|l|l|l|l|l|l|l|}
\hline \multicolumn{2}{|c|}{ América } & \multicolumn{2}{c|}{ Europa } & \multicolumn{2}{c|}{ Asia } & \multicolumn{2}{c|}{ Africa } \\
\hline Estado Unidos & 6 & Alemanha & 14 & Ceilão & 1 & Angola & 1 \\
Canadá & 3 & Austria & 2 & India & 6 & Congo & 1 \\
México & 2 & Bélgica & 11 & Hong - Kong & 1 & & \\
Argentina & 4 & França & 11 & Vietnam & 1 & & \\
Brasil & 21 & Espanha & 28 & & & & \\
Chile & 2 & Itália & 23 & & & \\
Colómbia & 6 & Holanda & 8 & & & \\
Guatemala & 1 & Portugal & 3 & & & \\
Perú & 1 & Suiça & 1 & & & \\
Uruguay & 1 & & & & & & \\
Venezuela & 1 & & & & & & \\
\hline
\end{tabular}

Fonte: Sánchez (1990) as cited in Silva (2017)

De acordo com Silva (2017):

o Serviço Social não se ergue como um projeto sociopolítico particular, mas como um campo de ligação ideológica da Igreja Católica e do Estado Novo, capturado e instrumentalizado pelo projeto conservador burguês, determinado, este sim, por um projeto sociopolítico de classe, caminhando com alguma tensão para a laicização. Concorda-se, desde logo, que dificilmente foram fatores intracientíficos, os que conduziram ao aparecimento do Serviço Social, enquanto disciplina académica em Portugal (p.289)

O curso de serviço social era organizado em três anos, requerendo habilitações de nível secundário. A formação curricular, descrita neste diploma, incluía três grandes temas: o estudo da vida física e das suas perturbações, estudo da vida mental e moral, estudo do funcionamento prático do Serviço Social e estágio. O curso versava, ainda, realização de inquéritos, visitas, relatórios e monografias.

O plano de estudos, incluía a realização de estágio ao longo dos três anos em várias áreas nomeadamente serviço de cirurgia, medicina, pediatria, puericultura, maternidade e consultas pré-natais, dispensários de profilaxia em higiene social, hospitais, fábricas, centros sociais e instituições especializadas em ensino familiar e doméstico. Além destas características, o serviço social era essencialmente e "obrigatoriamente" feminino 
dirigindo-se a mulheres, com um perfil vocacional e padrões morais associados à ideologia do Estado Novo (Silva, 2017).

Decorridos vinte anos, será a publicação do Decreto-Lei no .40 678, de 10 de julho de 1956, que anuncia no seu preâmbulo algumas alterações, particularmente a mudança para quatro anos na duração do curso, dando sinal de início de um novo projeto educativo. Mais tarde, através da Portaria $\mathrm{n}^{\circ} .15$ 972, de 18 de setembro do mesmo ano, o Ministério da Educação Nacional introduz, no $4^{\circ}$ ano a realização uma monografia social como esboço de trabalho sociológico. Nos anos seguintes, poderemos assistir a dois novos planos de estudo distando entre si aproximadamente uma década, o plano de estudos de 1960/61 e o plano de estudos de 1971/72. É efetivamente no ano letivo de 1960/61, segundo Fernandes (1985, p. 135), que se realiza a introdução dos métodos de intervenção social de caso, grupo e comunidades.

Os contornos sociais políticos vigentes em Portugal irão ser decisores no modelo de formação adotado para o serviço social português, diferindo deste modo da formação veiculada nas democracias ocidentais, pese embora a partir da década de 60 , força e reflexo da aproximação e conquista da democracia em Portugal na década de 70, alguns movimentos críticos e contestatários dentro do Serviço Social surgiram e insurgiram-se contra o modelo preconizado e defendido pelo Estado Novo para a profissão.

Assim poder-se-á dizer que o serviço social português tem tido ao longo do tempo várias influências:

- Até 1961 - Ensino de influência católica e sob influência humanista da corrente francófona;

- A partir de 1961 - continua com a influência francófona e passa a ser um ensino laico. Neste período até 1976 associa uma influência do serviço social dos EUA ao nível da intervenção comunitária.

- A partir de 1976 até quase a 1990- assume com maior influência o serviço social da América Latina e após esta data tem uma maior influência do serviço social anglo-saxónico, embora não seja unânime, pois temos escolas com orientações diferentes (Ferreira, 2014).

Volvidas algumas décadas desde a sua institucionalização, e de algumas conquistas adquiridas na profissão atualmente a formação em Serviço Social segundo Ferreira (2014, p.33): 
contempla os três ciclos de estudo: Licenciatura, Mestrado e Doutoramento e integra-se em quatro contextos institucionais diferenciados: Universidades, Universidade Católica Portuguesa, Institutos Politécnicos e Estabelecimentos de Ensino Superior Particular e Cooperativo. No que respeita à capacidade reconhecida para atribuição de graus académicos, a lei do ensino superior refere: «no ensino politécnico, são conferidos os graus de licenciado e de mestre. No ensino universitário, são conferidos os graus de licenciado, mestre e doutor» (DL - ${ }^{\circ} 115 / 2013$ art. $^{\circ} 4^{\circ}$, de 7 de agosto). O Decreto-lei no 115/2013 de 7 de agosto, define no art. ${ }^{\circ} 5^{\circ}$ o que se entende por grau de Licenciado 1 ; o art. ${ }^{\circ} 15^{\circ}$ define o que se entende por grau de Mestre, sendo este «conferido numa especialidade, podendo, quando necessário, as especialidades ser desdobradas em áreas de especialização»; e o art. $^{\circ} 28^{\circ}$ define o que se entende por grau de doutor e que é «conferido num ramo do conhecimento ou numa sua especialidade». A formação em Serviço Social ministrada no ensino politécnico conducente ao grau de licenciado deve valorizar especialmente a formação que visa o exercício de uma atividade de caráter profissional, assegurando aos estudantes uma componente de aplicação dos conhecimentos e saberes adquiridos às atividades concretas do respetivo perfil profissional» $\left(\mathrm{DL}, \mathrm{n}^{\mathrm{o}} 115 / 2013\right.$, art. ${ }^{\circ} 8^{\circ}$, de 7 de agosto). A formação ministrada no ensino universitário deve «(...) adotar valores similares aos das instituições de referência de ensino universitário do espaço europeu nas mesmas áreas, tendo em vista assegurar aos estudantes portugueses condições de mobilidade e de formação e de integração profissional semelhantes, em duração e conteúdo, às dos restantes Estados que integram aquele espaço (DL, nº 115/2013, art. $^{\circ} 9^{\circ}$, de 7 de agosto).

De acordo com Granja (2005) neste quadro no Brasil e no Canadá a formação é regulamentada por um núcleo comum de disciplinas e estágios obrigatórios, relativamente a Portugal não existe um núcleo comum obrigatório, pese embora e com a introdução do sistema de avaliação e acreditação dos ciclos de estudos, em 2007, que 
aprova o novo regime jurídico da qualidade do ensino superior, através do Decreto-Lei n. ${ }^{\circ}$ 369/2007, de 5 de novembro, é instituída pelo Estado Português a Agência de Avaliação e Acreditação do Ensino Superior (A3ES), que integra doutores em serviço social, que tem como fins a avaliação e a acreditação das instituições de ensino superior e dos seus ciclos de estudos, bem como o desempenho das funções inerentes à inserção de Portugal no sistema europeu de garantia da qualidade do ensino superior.

Para além disso a formação ministrada em Portugal, obedece ao conjunto alargado de instrumentos de natureza Internacional, Europeia e Nacional, nomeadamente Global Standards for the Education and Training of the Social Work Profession (General Assemblies of IASSW and IFSW, Adelaide, Austrália, 2004).

Em Portugal, a formação académica em serviço social, ao nível do $1^{\circ}$ ciclo de estudos (licenciatura) tem a duração de seis semestres com 180 créditos, pese embora em alguns cursos tem a duração de sete semestres com 210 créditos, e encontra-se em 17 instituições de ensino superior tal como se apresenta no Quadro 1:

Quadro 1. Licenciatura em Serviço Social nos sistemas de ensino público e privado (Portugal) - Total ECTS

Unidade Orgânica

ISCTE - Instituto Universitário de Lisboa

Faculdade de Psicologia e Ciências da Educação Universidade de Coimbra

$\left.\begin{array}{cc}\hline \begin{array}{c}\text { Faculdade de Ciências Sociais e Humanas- } \\ \text { Universidade dos Açores }\end{array} & 210 \\ \hline \begin{array}{c}\text { Instituto Superior de Ciências Políticas - } \\ \text { Universidade de Lisboa }\end{array} & 210 \\ \hline \begin{array}{c}\text { Escola de Ciências Humanas e Sociais - } \\ \text { Universidade de Trás-os-Montes e Alto Douro }\end{array} & 210 \\ \hline \text { Instituto Politécnico de Viseu } & 180 \\ \hline \text { Instituto Politécnico de Beja } & 180 \\ \hline \text { Instituto Politécnico de Leiria } & 180 \\ \hline \text { Instituto Politécnico de Castelo Branco } & 180 \\ \hline \text { Instituto Politécnico de Portalegre } & 180 \\ \hline \text { Instituto Superior Miguel Torga } & 210 \\ \hline \text { Faculdade de Ciências Humanas- Universidade } \\ \text { Católica Portuguesa - Lisboa } & 210 \\ \hline \begin{array}{c}\text { Faculdade de Filosofia e Ciências Sociais- } \\ \text { Universidade Católica Portuguesa- Braga }\end{array} & 210 \\ \hline \text { Universidade Lusíada } & 180 \\ \hline \text { Universidade Lusófona de Humanidades e } \\ \text { Tecnologias de Lisboa }\end{array}\right)$

\section{ECTS}

180

210 
$\mathrm{O} 2^{\circ}$ ciclo de estudos (mestrado) conducente ao grau de mestre tem 90 a 120 créditos e uma duração normal de quatro semestres curriculares e alguns cursos têm três semestres, e neste momento é ministrado nos seguintes estabelecimentos de ensino (Quadro2):

Quadro 2. Mestrado em Serviço Social nos sistemas de ensino público e privado (Portugal) - Total ECTS

\begin{tabular}{|c|c|}
\hline Unidade Orgânica & ECTS \\
\hline ISCTE - Instituto Universitário de Lisboa & 120 \\
\hline $\begin{array}{l}\text { Faculdade de Psicologia e Ciências da } \\
\text { Educação-Universidade de Coimbra }\end{array}$ & 90 \\
\hline $\begin{array}{c}\text { Instituto Superior de Ciências Políticas - } \\
\text { Universidade de Lisboa }\end{array}$ & 120 \\
\hline $\begin{array}{c}\text { Escola de Ciências Humanas e Sociais - } \\
\text { Universidade de Trás-os-Montes e Alto Douro }\end{array}$ & 120 \\
\hline Instituto Politécnico de Beja & 90 \\
\hline Instituto Superior Miguel Torga & 90 \\
\hline $\begin{array}{c}\text { Faculdade de Ciências Humanas - Universidade } \\
\text { Católica Portuguesa de Lisboa }\end{array}$ & 90 \\
\hline Universidade Lusíada & 120 \\
\hline $\begin{array}{l}\text { Universidade Lusófona de Humanidades e } \\
\text { Tecnologias de Lisboa }\end{array}$ & 120 \\
\hline
\end{tabular}

O programa doutoral ( $3^{\circ}$ ciclo de estudos) em Serviço Social tem um ano curricular organizado em dois semestres e dois anos (podendo ser prorrogado por mais um ano) de elaboração de uma tese original adequada à natureza do ramo de conhecimento ou da especialidade, e é lecionado tal como se apresenta no quadro 3 nas seguintes instituições:

Quadro 3. Doutoramento em Serviço Social nos sistemas de ensino público e privado (Portugal) - Total ECTS

\begin{tabular}{c|c} 
Unidade Orgânica & ECTS \\
\hline ISCTE - Instituto Universitário de Lisboa & 180 \\
\hline $\begin{array}{c}\text { Faculdade de Psicologia e Ciências da Educação-Universidade de } \\
\text { Coimbra e Faculdade de Ciências Humanas - Universidade Católica } \\
\text { Portuguesa de Lisboa - Programa Interuniversitário }\end{array}$ & 180 \\
\hline Universidade Lusíada & 180 \\
\hline Fonte: Direção Geral Ensino Superior, 2021
\end{tabular}

No que diz respeito ao quadro de princípios e fundamentos teórico-científicos para o Serviço Social na atualidade encontram sustentação nas orientações da Declaração de Bolonha, quando esta propõe como aquisição de competências profissionais ao nível do: 
Quadro 4. Competências Profissionais nos $3^{\circ}$ ciclos da formação em Serviço Social

\begin{tabular}{|c|c|c|}
\hline $1^{\circ}$ Ciclo Licenciatura & $2^{\circ}$ Ciclo Licenciatura & $3^{\circ}$ Ciclo \\
\hline $\begin{array}{l}\text { 1.Conhecimento e } \\
\text { compreensão num } \\
\text { determinado campo de } \\
\text { estudo quer a nível } \\
\text { teórico, quer a nível prático } \\
\text { (conhecimento da actividade } \\
\text { do seu campo de estudo) } \\
\text { 2.Aplicar os seus } \\
\text { conhecimentos e } \\
\text { compreensão a um nível } \\
\text { profissional e que } \\
\text { demonstrem as suas } \\
\text { competências através da } \\
\text { resolução de problemas } \\
\text { dentro do seu campo de } \\
\text { estudo. } \\
\text { 3.Capacidade para recolher e } \\
\text { interpretar informação } \\
\text { relevante e efectuar análises } \\
\text { capazes de serem usadas na } \\
\text { resolução de problemas } \\
\text { sociais, científicos ou } \\
\text { éticos. } \\
\text { 4. Transmitir informação, } \\
\text { ideias, problemas e soluções } \\
\text { quer a um público } \\
\text { especialista, quer a um } \\
\text { público não-especialista. } \\
\text { 5. Capacidade de } \\
\text { aprendizagem necessária } \\
\text { para continuarem a estudar } \\
\text { com um } \\
\text { elevado grau de autonomia. }\end{array}$ & $\begin{array}{l}\text { 1.Conhecimento e compreensão de } \\
\text { matérias que complementem e } \\
\text { acrescentem algo mais ao tipo de } \\
\text { conceitos associados ao primeiro } \\
\text { ciclo, e que forneçam a base e } \\
\text { originalidade necessárias para o } \\
\text { desenvolvimento de aplicação de } \\
\text { ideias num contexto de pesquisa. } \\
\text { 2.Aplicar o seu conhecimento e } \\
\text { compreensão e capacidade de } \\
\text { resolução de problemas em } \\
\text { ambientes novos ou pouco } \\
\text { familiares em contextos mais } \\
\text { abrangentes. } \\
\text { 3.Capacidade para integrar } \\
\text { conhecimento e lidar com a } \\
\text { complexidade de forma a formular } \\
\text { conclusões com informação } \\
\text { limitada ou incompleta, mas que } \\
\text { incluam reflexões ao nível das } \\
\text { responsabilidades sociais e éticas. } \\
\text { 4.Transmitir as suas conclusões tal } \\
\text { como os conhecimentos e } \\
\text { argumentos que } \\
\text { estão na base de tais conclusões } \\
\text { quer a uma audiência de } \\
\text { especialistas, quer a } \\
\text { uma audiência de não especialistas, } \\
\text { e de uma forma perfeitamente clara. } \\
\text { 5. Capacidade de aprendizagem } \\
\text { necessária para continuarem a } \\
\text { estudar de uma } \\
\text { forma dirigida a ele próprio } \\
\text { (estudante) ou autónoma }\end{array}$ & $\begin{array}{l}\text { 1.Compreensão sistemática } \\
\text { de um campo de estudo, e } \\
\text { dominem totalmente as } \\
\text { técnicas e métodos de } \\
\text { pesquisa associados a esse } \\
\text { campo. } \\
\text { 2.Habilidade para conceber, } \\
\text { projectar, implementar e } \\
\text { adaptar um processo de } \\
\text { pesquisa. } \\
\text { 3.Contribuição através de } \\
\text { uma pesquisa original que } \\
\text { tenha desenvolvido um corpo } \\
\text { de trabalho considerável, } \\
\text { algum do qual tenha sido } \\
\text { alvo de reconhecimento } \\
\text { mérito nacional e } \\
\text { internacional. } \\
\text { 4.Efectuar análises críticas, } \\
\text { avaliação e síntese de ideias } \\
\text { novas e complexas. } \\
\text { 5.Comunicar com os seus } \\
\text { colegas, com o corpo } \\
\text { académico e com a sociedade } \\
\text { em geral sobre a sua área de } \\
\text { trabalho. } \\
\text { 6. Promover no contexto } \\
\text { académico e profissional, } \\
\text { avanços tecnológicos, sociais } \\
\text { e culturais numa sociedade } \\
\text { baseada no conhecimento. }\end{array}$ \\
\hline
\end{tabular}

Num processo de formação curta como se carateriza o atual processo de Bolonha, em áreas de formação que intervêm com a pessoa humana e que tomam como quadro estruturante os direitos humanos, a formação prática articulada com o exercício profissional pode ser renovada sendo e no caso particular o serviço social sempre foi e é pioneiro neste modelo articulado entre teoria e prática. "The challenge to interpret social work from an international perspective requires an understanding of practice context and to view this beyond state welfare provision" (Spolander et al., 2014, p.303).

O serviço social no quadro das ciências sociais e humanas consiste numa formação cujo perfil profissional é definido pela sua dimensão operativa, cuja capacidade de 
concretização e de ação deve estar cada vez mais baseada em instrumentos e ferramentas técnicas e científicas, sendo que no presente o serviço social encontra-se num estádio de consolidação da investigação ao nível de linhas de pesquisa, projetos de investigação e carreira de investigador.

A formação dos assistentes sociais, pressupõe a construção de estruturas cognitivas de conhecimento teórico interdisciplinar, mas também um saber operacional que investe o conhecimento teórico na ação e o transforma pelo confronto com o real. Esta formação exige estágio em contexto real de trabalho, articulado com processos de aprendizagem em situação de prática simulada. Os estágios são uma fonte tradicional da construção identitária inicial dos assistentes sociais que desde o início da formação permite aos estudantes analisar, refletir e experimentar as efetivas competências dos assistentes sociais e construir a identidade e autonomia profissional, fazer as escolhas numa dinâmica de construção identitária individual e coletiva com uma interação permanente entre a teoria, a realidade social e a prática profissional (Granja, 2011).

Pensar a formação em serviço social no quadro da globalização económica e social, bem como do Espaço Único Europeu, assume particular desafio e estímulo não só para os investigadores sociais, mas também para os assistentes sociais que diariamente são chamados a intervir na diversidade de dinâmicas sociais vivenciadas na sociedade atual (Ferreira, 2008).

\section{Ser assistente social: A identidade do Serviço Social}

O Serviço Social é uma área de conhecimento científico que tem os seus fundamentos éticos nas questões dos direitos das pessoas, da dignidade, da justiça social e da autodeterminação humana (Banks, 2008). Os assistentes sociais respondem a problemas que resultam das dinâmicas dos contextos socioeconómicos, políticos, mas que afetam trajetórias, contextos de vida não apenas individuais, mas também coletivos. Esta intervenção pressupõe uma formação que desenvolva a componente reflexiva e analítica, a interação permanente entre a teoria, a realidade social e a prática profissional (Pena, 2012).

Para que este saber agir se mantenha dentro daquilo que é ser assistente social, para além de competências científicas, técnicas - operativas, será fundamental que detenha de competências ético relacionais, seja emocionalmente inteligente (Pena, 2012) de modo que consiga gerir os seus sentimentos e os dos outros (Howe, 2008) ou de acordo com Ander Egg (1985): 
a convicção e confiança em que as pessoas têm capacidade para se levantarem da sua situação e terem um papel na sua própria promoção e capacidade para motivar, capacidade de escuta, facilidade de comunicação, abertura e disponibilidade para os outros, maturidade emocional e capacidade para vencer dificuldades (pp.197199).

Porque o assistente social intervém junto de pessoas e o que o sustenta, confere validade e reconhecimento a esta intervenção, é precisamente a relação que estabelece com as pessoas nas quais intervém, e que em conjunto constrói e reconstrói os projetos de vida dessas pessoas, numa perspetiva de interdisciplinaridade e de horizonte temporal, assente na capacitação por oposição a ações assistencialistas ou paternalistas, torna-se fulcral a reflexividade da ação, de modo permanente e contínuo, seja esta realizada de modo individual ou coletivo, assumindo a formação contínua e a própria supervisão um papel de "auxílio" a esta reflexividade do pensamento e da intervenção no assistente social.

Para intervir na realidade social o assistente social necessita de conhecer e para isso terá que investigar, analisar, refletir, colocar em prática a sua dimensão mais teorizante da profissão, numa ótica de interdisciplinaridade e de não subalternidade no que concerne à sua relação com as ciências sociais (Ferreira, 2014). Se o trabalho desenvolvido na área social é complexo e variável, nomeadamente no serviço social, de acordo com a cultura, contextos sociais e económicos dos seus intervenientes, compreendê-lo exige conhecimento e compreensão efetiva desses contextos (Payne 2002).

A leitura da prática é feita com base em orientações teóricas, embora com um objetivo comum, encontrar hipóteses que expliquem certos tipos de intervenção e que visam obter determinados resultados ao nível da pessoa, do comportamento, da rede social e outras. É uma forma de organização «mental» do conhecimento que posteriormente define e orienta os métodos e técnicas a utilizar pelo assistente social (Stepney, 2000, p. 21). Deste modo, o papel das teorias no serviço social são o de “orientar, procurar e construir conhecimentos crítica e reflexivamente, que permitam a construção epistemológica do que lhe é próprio e específico" (Restrepo, 2003, pp. 21-45).

Também Stepney refere "prática-teórica" como um aspeto central da profissão de assistente social. Parton (2000) tal como acontece com Fook (1993) defendem que a construção de um novo projeto para o serviço social que implica a assunção de três aspetos, nomeadamente: 
1. o formativo (a formação em Serviço Social);

2. a aplicação prática dos conhecimentos adquiridos em contexto formativo (que aliam o aspeto formativo à prática profissional, num processo de retroalimentação)

3. as estratégias metodológicas de intervenção profissional (que permitem a construção do conhecimento através do processo reflexivo do profissional numa avaliação da sua prática, transformando-a em produtos teóricos e em produtos políticos).

Segundo Sheppard, (1995 as cited in Ferreira, 2014), quando valoramos a importância de um determinado conhecimento para o serviço social, não podemos ter apenas em conta a sua validade teórica, segundo a qual um conhecimento é válido em termos epistemológicos e metodológicos, mas deve-se ter também em conta a sua validade prática, referindo-se à consistência e satisfação do objetivo e dos propósitos do serviço social. Para Fook (2002) o conhecimento empírico em serviço social é imprescindível para o entendimento da forma como as estruturas sociais regulam a vida individual.

Os estudos sobre a identidade do serviço social têm vindo a caracterizá-lo como uma profissão socialmente construída, multidimensional nas suas práticas e nos objetos da sua prática e ainda, segmentada. Segmentada em termos de saberes teóricos e segmentada em termo das suas práticas quotidianas. Práticas profissionais que se encontram, por vezes, enraizadas nas particularidades do seu campo de intervenção e nas características da organização onde o profissional se encontra legal e juridicamente enquadrado, sem se construir num todo organizado do foro metodológico e operativo (Santos, 2011, p. 1).

Sem esta identidade assumida o assistente social paralisa, desresponsabiliza-se, perde a autonomia própria de que precisa para se afirmar como tal.

Destarte o que confere especificidade à intervenção dos profissionais que intervém nas relações sociais é o conhecimento construído que tem como finalidade não apenas a compreensão e explicação do real, mas a instrumentação de um determinado tipo de ação sobre esse real, o que exige reflexividade, crítica teórica, social.

O desenvolvimento de um ensino prático reflexivo pode facultar novas formas de pesquisa sobre a prática profissional e de educação para essa prática, criando um momento de ímpeto próprio, ou mesmo algo que se transmita por contágio entre professor e estudante (Schön, 1987). 
Wilson (2008, as cited in Pena, 2012) menciona que a prática reflexiva surge como um meio dos assistentes sociais sustentarem a prática baseada na relação, "envolvendo o pensamento holístico, que integra factos e sentimentos, compreensão artística e científica, assim como a perspetiva subjetiva e objetiva" atendendo "às necessidades únicas e específicas do indivíduo".

A reflexão tem adquirido um profundo reconhecimento na prática do serviço social, não só para sustentar e apoiar os assistentes sociais na identificação das suas forças e fraquezas, mas de modo a superar o hiato existente, por vezes, entre a teoria e a prática profissional e a ampliar o corpo de conhecimento do serviço social integrados na prática profissional. O grande desafio centra-se na urgência de um (re) posicionamento do serviço social erigido num pensamento e ação ético político e reflexivo, no sentido de se convocar sinergias que produzam uma verdadeira consciência humana e social.

Atendendo à diversidade de problemas complexos com os quais os assistentes sociais se deparam no seu quotidiano profissional, tal implica a apropriação de metodologias críticas e reflexivas que lhes possibilitem a produção de conhecimento que, por um lado, coadjuve na compreensão e interpretação desses problemas e contribua para a capacitação dos assistentes sociais na dinamização de soluções e de respostas eficazes às problemáticas emergentes; por outro lado, recupere e consolide a identidade profissional, legitimando o seu lugar (Baptista, 2001) e consequentemente, reconstrua e amplie os seus contextos de ação de forma competente e útil nas situações práticas o que implica pensar teoricamente. Se não o fizer a intervenção social converte-se numa forma de puzzle desorganizado de experiências, que tem como resultado final, uma prática espontânea (Viscarret, 2008, p. 20).

\section{Metamorfoses e Ambivalências Societais: Desafios e Oportunidades para o Serviço Social}

No século XXI o serviço social confronta-se com desafios endógenos e exógenos, conducentes à inevitabilidade de uma ação crítica pós-estruturalista e sistémica, que permita fazer face a uma realidade de profundas transformações sociodemográficas e implicações no modelo de bem-estar.

Com base na teoria social de Marx, entende-se que, perante o atual cenário em que desabrocham diretrizes governamentais de assistencialismo da "questão social", torna-se urgente refletir sobre como se implementa a adequação do significado da "questão social" entre os assistentes sociais concretamente envolvidos nesta mudança de paradigma. Para 
Marx (1978, p. 120) "a anatomia do homem é a chave da anatomia do macaco"; o mais complexo explica o menos complexo e as formas superiores de desenvolvimento explicam as formas inferiores de desenvolvimento".

Neste sentido, de acordo com Iamamoto (2004, p. 236) "a profíssão de Serviço Social não se explica por si mesmo, senão a partir de sua inserção na sociedade”. Com a perspetiva de análise crítica da realidade mediante o legado de Marx, o Serviço Social tem feito um enorme esforço para romper com as visões internas e focalizadas isentas de análises sobre as determinações das relações capitalistas na profissão.

Historicamente, sabe-se que a questão social esteve na base da instituição das práticas dos assistentes sociais, que se baseavam numa luta de classes face à burguesia, então organizada, lutando pela justiça social, a equidade, a defesa dos direitos (civis, políticos e sociais) dos trabalhadores, passando a questão social a ser considerada como a expressão das desigualdades sociais.

É no desenvolvimento dessa prática, em contexto de conflito social, que surgem as políticas sociais como instrumentos necessários para legitimar as conquistas da classe trabalhadora e, consequentemente, reduzir o conflito.

O surgimento do Estado de Bem-Estar social, ligada à proteção social, permitiram a criação da base de sustentação funcional-ocupacional do Serviço Social (Montaño, 1997).

Contudo, a nova questão social trazida pelas questões da globalização, caracterizada pela redução da força de trabalho, pelo desemprego estrutural ou pelo trabalho precário, e a minimização dos direitos sociais através da erosão do Estado Social, outrora conquistado, passa a ter novos contornos e significados para as políticas sociais e, consequentemente, para o Serviço Social (Faleiros, 1999, 2006; Montaño, 1997; Mouro, 2009).

O Estado por sua vez perdeu força perante as organizações multinacionais, a juntarse a esta situação os grandes deficits levam a que passe a privilegiar as condições gerais de financiamento das grandes despesas financeiras e de serviços ao funcionamento das empresas, relegando para segundo plano as políticas universais.

Assim, este modelo económico-político torna-se a causa dos enormes efeitos nocivos dos direitos sociais conquistados. Neste contexto, o processo de globalização económica tem-se revelado um verdadeiro catalisador dos movimentos de exclusão dentro também do próprio Estado-Providência, intensificando a miséria e a degradação 
das condições e dos postos de trabalho por todo o mundo, como afirma Nascimento (1997, p.89-90):

A dimensão mais central nos estudos em torno da exclusão é ainda a económica, e, mais precisamente, a do mercado de trabalho. A maioria dos estudos relacionam sempre as situações de exclusão com o crescimento do desemprego e, por consequência, com o aumento da desigualdade social. São as metamorfoses no mundo do trabalho, os impactos recentes das inovações tecnológicas, a desterritorialização provocada pelos movimentos de internacionalização da economia e o surgimento do desemprego estrutural e de longa duração, sobretudo na Europa e na América Latina, os responsáveis primeiros, primordiais da situação de exclusão. O excluído é, em primeiro lugar, alguém que está fora ou foi posto fora do mercado de trabalho.

Ao mesmo tempo que a sociedade faz uma apelo ao consumo, garantidos por um sistema de crédito manipulado pelas grandes companhias financeiras e o marketing enfatiza não as necessidades mas os objetos fabricados através da imagem de marca veiculados por meios de comunicação, que estimulam ao consumo, a universalização genérica dos direitos sociais é questionada enquanto geradora de gastos sociais em benefícios gerais que criam dependência e ineficiência para o acesso e preparação para o mercado, sendo que e segundo Bauman (2008) as relações da atualidade reconfiguram-se obedecendo aos princípios do consumismo, insegurança, livres de compromissos, relações flexíveis e ambíguas, no entanto presas psicológica e espacialmente pelo medo do outro.

O Serviço Social hoje tem de preparar assistentes sociais capacitados para acompanhar a mudança do modelo de Estado e sociedade. Segundo James (1986):

In seeking to understand the impact of a neoliberal approach on social work practice it is important for us to reflect on the uniqueness of social work which is not due to a discrete knowledge base, but rather its perspective on people's problems in «living» and therefore '(...) the inter-connectedness and interdependence of individuals with their society, believing that «private troubles» and «public issues» are intimately related. The knowledge base, therefore, is 
derived from research about individuals and society and, more importantly, about the dynamic relationship between the two. (James, in Spolander et al., 2014, p. $305)$.

Netto (2000) afirma que a formação dos assistentes sociais enfrenta o paradoxo de formar aqui e agora para intervir em problemas que estão a mudar de forma acelerada e para responder a necessidades previsíveis, mas virtuais. Este autor refere ainda o facto de ser uma formação em que obrigatoriamente se joga com valores porque se intervém socialmente, se decide um sentido para a ação e para as mudanças que se propõem, se reconhecem e identificam as regularidades e determinações sociais, devendo o manto identitário estar bem definido, pois caso contrário por pressão ou força dos juízos de valor provenientes do senso comum instalado, da emergência na ação e constrangimentos das políticas e/ou falta de recursos poderá comprometer os pressupostos da ação em serviço social (Granja, 2014).

Como forma de se reposicionar e colocar-se numa postura de movimento contrahegemónico frente aos novos desafios, o serviço social deverá privilegiar essa dimensão política através de um investimento no conhecimento da realidade da nova questão social e dos processos que a geram. A investigação em serviço social torna-se, então, essencial na contemporaneidade (Guerra, 2001; Iamamoto, 1996; Montaño, 1997; Mouro, 2009).

\section{Conclusão}

O propósito da profissão, assistente social, incorre precisamente na mudança social, no trabalhar as pessoas para que se superem a si próprias numa perspetiva de horizonte temporal e de lógica coletiva, sendo que as ações desenvolvidas pelo assistente social pretendem ter impacto não apenas no imediato, mas a longo prazo, um sentido prospetivo, de modo que o bem-estar assim como a equidade e justiça social sejam uma realidade alcançável por e para todos.

Para isso, é fundamental que o assistente social continue a investir na consolidação do projeto ético político do serviço social bem como no quotidiano do seu trabalho profissional, na relação profissional, na formação contínua, e que sobretudo progrida em direção ao desenvolvimento da sociabilidade pública capaz de reestabelecer a política como espaço de criação e generalização dos direitos humanos, sob o seu manto identitário, tendo por base uma formação que lhe "confira sentido e significado aos 
códigos especializados da profissão e que permitem aos futuros profissionais efetuar as suas escolhas" (Granja, 2011, p.165).

Em suma, para fazer face ao novo paradigma civilizacional e pedagógico, mas mantenha o que o permite ser assistente social é imprescindível que a formação inicial em serviço social preconize um ensino reflexivo, assente na consolidação e interiorização de novas formas de pesquisa sobre a prática e de educação para essa prática, e por seu turno potencie a aquisição de uma postura crítica e reflexiva sobre a profissão na sociedade, de forma a sedimentar o processo de construção de identidade, articulando teoria com a prática, e por seu turno colmate as fragilidades na ação e na tomada de decisões, e desenvolva competências nos contextos e para os contextos de intervenção uma intervenção integrada, crítica e interdisciplinar, promotora de relações interpessoais saudáveis, de interajuda, de autonomia.

\section{Referências Bibliográficas}

Amaro, M. (2012). Urgências e Emergências do Serviço Social: Fundamentos da profissão na contemporaneidade. ( $\left.1^{\mathrm{a}} \mathrm{ed}\right)$. Universidade Católica Editora (UCE).

Amaro, M. (2009). Identidades, Incertezas e Tarefas do Serviço Social Contemporâneo. Locus SOCI@L. Journal of Social Worl, Social Policy and Society,2, 29 $-46$.

Ander-Egg, E. (1995). Introdução ao Trabalho Social (24a ed).Vozes.

Banks, S. (2008). Ética Prática para as Profissões do Trabalho Social (12a ed). Porto Editora. Editora.

Baptista, M. (2001). A investigação em Serviço Social (1 ${ }^{\mathrm{a}}$ ed). CPIHTS/Veras

Bauman, Z. (2008). Amor Líquido (11 a ed). Relógio D'Água.

Direção Geral Ensino Superior. (2021). Cursos e Instituições. https://www.dges.gov.pt/pt/pesquisa_cursos_instituicoes.

Faleiros, V. (1999). Estratégias em Serviço Social (2ª . ed). Cortez.

Fernandes, E. (1985). Elementos para uma cronologia do Serviço Social em Portugal. Revista Intervenção Social, 2 (3), 143-148.

Ferreira, J. (2014). Serviço Social: profissão e ciência. Contributos para o debate científico nas ciências sociais. Trabajo Social Global, 27 (2), 329-341.

Ferreira, J. (2011). Contributos para o debate da epistemologia em serviço social. Trabajo Social Global, 2 (1), 67-78.

Ferreira, J. (2008, Novembro 6-8). Pensar a formação em Serviço Social no quadro da Globalização e do Espaço Único Europeu. (Comunicação). Congresso de O Serviço Social no Séc.XXI: Desafios e Oportunidades. Instituto Superior de Serviço Social de Lisboa da Universidade Lusíada de Lisboa. 
Fook, J. (2002). Social Work. Critical Theory and Practice (1st ed). Sage Publications Lda.

Guerra, Y (2001). A instrumentalidade do serviço social. Revista Serviço Social e Sociedade, 62, 1-16.

Global Standards for the Education and Training of the Social Work Profession (2004). General Assemblies of IASSW and IFSW, Adelaide, Austrália.

Granja, B. (2011). A competência reflexiva processual em serviço social na ação profissional junto às populações. Cadernos de Pesquisa, 41(143), 428-453.

Granja, B. (2005). O estágio curricular como espaço nuclear na construção das competências profissionais: o caso do serviço social. Construindo o Serviço Social, 16, 7-30.

Iamamoto, M. (2004). O Serviço Social na Contemporaneidade: Trabalho e Formação ( $7^{\mathrm{a}}$ ed). Cortez.

Howe, D. (2008).The Emotionally Intelligent Social Worker (4th ed). Palgrave Macmillan

Marx, K. (1978). O Capital (1 $1^{\mathrm{a}}$ ed). Nova Cultural.

Montaño, C. (1997). O Serviço Social frente ao neoliberalismo. Mudanças na sua base de sustentação funcional-ocupacional. Revista Serviço Social e Sociedade,53, 9-33.

Mouro, H. (2009). Modernização do Serviço Social - Da Sociedade Industrial à Sociedade do Risco ( $1^{\mathrm{a}}$ ed). Almedina.

Nascimento, E. (1997) Globalização e Exclusão Social: fenômenos de uma nova crise da modernidade. Revista Desafios da Globalização, 74-93.

Netto, J. (2000). O serviço social hoje. Revista Intervenção Social, 7, 53-57.

Payne, M. (2002). Teoria do Trabalho Social Moderno. (2nd ed). Quarteto.

Parton, N. (1996). Social Theories, Social change and Social Work: Towards a new practice, 39 (4), 468-478.

Pena, M.J. (2012). Relação Profissional: Utopia ou Realidade? [Tese de Doutoramento em Serviço Social. ISCTE-IUL]. Repositório Institucional do ISCTE-IUL. http://hdl.handle.net/10071/6348

Pontes, R. N. (2002). Mediação e Serviço Social: Um estudo preliminar sobre a categoria teórica e sua apropriação pelo serviço social ( $\left.1^{\mathrm{a}} \mathrm{ed}\right)$. Cortez.

Restrepo, O. (2003). Reconfigurando el trabajo social. Perspectivas y tendências contemporaneas $\left(1^{\mathrm{a}} \mathrm{ed}\right)$. Editorial Espacio.

Santos, C. (2011). Profissões e Identidades Profissionais $\left(4^{\mathrm{a}}\right.$ ed). Imprensa Universidade de Coimbra.

Silva, J. (2008). Em nome do sujeito: Serviço Social, uma profissão de Ajuda na Encruzilhada de uma nova era ( $1^{\mathrm{a}}$ ed). Edições Copy

Silva, T. (2017). A primeira escola de Serviço Social em Portugal: o projeto educativo fundador e a configuração do campo de conhecimento (1935-1955). [Tese de Doutoramento em Serviço Social. Universidade Lusíada]. Repositório Institucional das Universidades Lusíada http://hdl.handle.net/11067/2695 
Spolander, G., et al. (2014). The implications of neoliberalism for social work: Reflections from a six-country. International research collaboration. http://isw.sagepub.com/content/57/4/301 http://www.sagepublications.com.

Stepney, P. et al. (2000). Social Work Models, Methods, and theories: A Framework for Practice (1st ed). Russell House Publishing.

Viscarret, J. (2009). Modelos y métodos de intervención en Trabajo Social (7 $\left.7^{\mathrm{a}} \mathrm{ed}.\right)$. Alianza Editorial. 